\title{
Measuring the intakes of foods and nutrients of marginal populations in north-west Mexico
}

\author{
MI Ortega ${ }^{1, *}$ and ME Valencia ${ }^{2}$ \\ 'Human Nutrition Department, Centro de Investigación en Alimentación y Desarrollo, A.C., Mexico: \\ ${ }^{2}$ Nutrition Division, Centro de Investigación en Alimentación y Desarrollo, A.C., Mexico
}

\begin{abstract}
Objective: To describe methodological issues regarding the measurement of food intake of marginal populations in the north-west of Mexico.

Methods: Dietary data from three sources were analysed. The Sonora State Food Basket Study (505 individuals from all ages, both sexes, high, medium and low income, and from urban and rural settings), 144 individuals from rural Indian communities, and 152 low-income urban women. Methods of dietary data collection were single 24-hour recalls for the first two studies, and four non-consecutive 24-hour recalls as well as a food-frequency questionnaire (FFQ) for low-income urban women.

Results: The food patterns in the three studies showed similar core foods; however, food diversity resulted in 19, 13 and 57 different foods reported by $90 \%$ of the population in the state, Indian communities and urban women, respectively. Mean intakes of selected food components in the sample of urban women vs. a representative sample of the population of the state were similar, although smaller variation in consumption was observed in urban women with repeated 24-hour recalls. Inter-individual variation in intake of food components was similar in the state and urban women samples, but the Indian communities showed lower coefficients of variation (CVs). Use of four 24-hour recalls decreased the inter-individual variation in food component intakes of low-income urban women, especially for vitamin intakes. The FFQ did not show an additional decrease in inter-individual variation for macronutrients, but reduced even more the CVs for vitamins. Intra-individual variation was higher than inter-individual variation for urban women's intakes when estimated by repeated 24-hour recalls. This effect was reversed when estimated by duplicate food frequencies. Ratios of intra-individual to inter-individual variation in food intake were lower for Mexican when compared with US women. These results should be considered, especially for association analysis of low-income women's diets and health outcomes.
\end{abstract}

As in many of the studies before the 1990s, food intake in the population of north-west Mexico has traditionally been measured using a single 24-hour recall. The main reasons for this are the limited resources for community nutritional diagnostics to allow for repeated measures of the diet of individuals, as well as the logistics of the fieldwork. Since the purpose of the dietary diagnostics was mainly the description of food patterns or the determination of mean intakes, the error of estimation of the variance and the usefulness of individual intakes in studies of association were of little concern.

In the last decade, however, concern about the prevalence of chronic diseases ${ }^{1,2}$ and the importance of diet-disease relationships have aroused researchers' awareness of the importance of error measurement and the problems of representativeness when a single 24-hour recall is the method of choice.
Development and validation of methods like the foodfrequency questionnaire (FFQ) have been made at national and regional levels ${ }^{3,4}$; however, culturally adapted questionnaires are rare. As a consequence, single and low-cost interviews like the 24-hour recall must remain in use.

What we need, as Beaton and others ${ }^{5,6}$ have discussed, is knowledge of the magnitude of error associated with the measurement of food intake using the available methods, in order to correct our intended association analysis.

The aim of this study is to describe methodological issues regarding measurement of the food intake of marginal populations in the north-west of Mexico. In this context, we describe the inter-individual and intraindividual variation in the estimation of food intake in the population of north-west Mexico, as well as the pattern of food intake by season. 


\section{Methods}

We used the information available from food intake studies in the population of the state of Sonora, located in the north-west of Mexico. Several authors ${ }^{7,8}$ and national studies, using economic activities and health indicators, have defined this part of the country as a region with low levels of poverty (as compared with the southern region of the country), as well as low levels of stunting?. High mortality and morbidity rates in adults are related to chronic diseases such as cardiovascular problems and type 2 diabetes ${ }^{1,7}$.

This study analysed dietary information from three studies. The Sonora State Food Basket Study ${ }^{10}$ (late 1980s) included 505 individuals from all ages, both sexes, high, medium and low income, and from urban and rural settings. We also used dietary data from 152 low-income urban women from a study of dietary risk factors of women in the north-west of Mexico ${ }^{4}$. Finally we included dietary data from rural Indian communities ${ }^{11}$ collected as part of a study on the aetiology of type 2 diabetes.

The dietary data collection method used in the three studies was the 24-hour recall. Single 24-hour recalls were used in the state food basket study and the Indian community study. Regarding the study on dietary risk factors of women, the data collection involved four non-consecutive 24-hour recalls distributed along the four seasons of the year, as well as an FFQ designed and validated for that group of women.

For 24-hour data collection, food models and pictures were used, as well as home measures of containers. Analysis of dietary components relied upon data in a food dictionary compiled at Centro de Investigación en Alimentación y Desarrollo ${ }^{12}$ (CIAD) from several food composition tables, such as those of the US Department of Agriculture $^{13}$, the National Nutrition Institute in Mexico ${ }^{14}$, and the food composition tables developed at CIAD for regional foods.

The analysis included descriptive statistics (mean,

Table 1 Nutrients in the diets of women in the Sonora State Food Basket Study and urban women in the dietary risk factors study. Values are given as mean \pm standard deviation

\begin{tabular}{lcc}
\hline & $\begin{array}{c}\text { Food basket } \\
\text { women } \\
(n=141) \\
(1980 \mathrm{~s})\end{array}$ & $\begin{array}{c}\text { Urban women } \\
(1990 \mathrm{~s})\end{array}$ \\
\hline Nutrient & $1856 \pm 922$ & $1940 \pm 521$ \\
\hline Total energy (kcal) & $35 \pm 9$ & $36 \pm 6$ \\
Fat energy (\%) & $11 \pm 4$ & $11 \pm 2$ \\
Saturated fat energy (\%) & $51 \pm 10$ & $51 \pm 7$ \\
Carbohydrate energy (\%) & $365 \pm 308$ & $329 \pm 202$ \\
Cholesterol (mg) & $35 \pm 22$ & $30 \pm 13$ \\
Fibre (g) & $639 \pm 1209$ & $1059 \pm 1527$ \\
Vitamin A ( $\mu$ g RE) & $71 \pm 100$ & $81 \pm 56$ \\
Vitamin C (mg) & & \\
\hline
\end{tabular}

$\mathrm{RE}$ - retinol equivalents. standard deviation (SD), coefficient of variation (CV)) and analysis of variance, and was performed using SPSS 7.0 software.

\section{Results and discussion}

The data on food patterns from the Sonora State Food Basket Study reveal that the food intake of the majority of the Sonoran population seems to be quite simple, when compared with the food intake of those populations in developed countries. In fact, $50 \%$ of the population have a food pattern composed mainly of beans, corn or wheat tortilla, eggs, meat (mostly chicken, sausages, bologna and small amounts of beef), milk, sugar, tomatoes and potatoes. It is noteworthy that fruits and vegetables are consumed infrequently and in small quantities.

The rural Indian community is one of the lowest-income populations in the state of Sonora. The food pattern of $90 \%$ of 144 adult Indians reveals a very simple pattern of consumption. Thirteen foods were consumed by $90 \%$ of the sample and they are mainly the staple foods common to the Sonora population, including beans, corn and wheat tortilla, eggs, milk, coffee, sugar and potatoes.

The food patterns for the whole population of Sonora and the rural Indian communities were based on the frequency of consumption of foods using a single 24-hour recall.

Even though the same core foods were present in the diets of urban women from the study on dietary risk factors, the food pattern showed a wider variety ( 57 foods consumed for $90 \%$ of the sample), probably because intake estimation was based on four 24-hour recalls spread across the four seasons of the year.

Table 1 compares intakes of selected nutrients between women in the Sonora State Food Basket Study and urban women in the dietary risk factors study. Similar intakes of total energy and percentage of energy provided by macronutrients were found. However, the SD decreased for the study on urban women when multiple 24-hour

Table 2 Between-subject coefficients of variation in adult diets (single 24-hour recall)

\begin{tabular}{|c|c|c|c|c|}
\hline \multirow[b]{2}{*}{ Nutrient } & \multicolumn{2}{|c|}{$\begin{array}{c}\text { Sonora } \\
\text { State Food } \\
\text { Basket Study }\end{array}$} & \multirow{2}{*}{$\begin{array}{l}\text { Urban women } \\
\text { from dietary } \\
\text { risk factors } \\
\text { study }\end{array}$} & \multirow{2}{*}{$\begin{array}{c}\text { Rural } \\
\text { (Indian) }\end{array}$} \\
\hline & Urban & Rural & & \\
\hline Energy & 49.7 & 48.8 & 38.1 & 23.0 \\
\hline Protein & 55.2 & 62.8 & 42.4 & 25.6 \\
\hline Carbohydrate & 48.2 & 50.6 & 43.4 & 22.4 \\
\hline Total fat & 62.3 & 60.3 & 48.3 & 32.8 \\
\hline Cholesterol & 81.8 & 89.3 & 87.7 & 101.2 \\
\hline Fibre & 63.4 & 60.4 & 58.7 & 30.2 \\
\hline Vitamin A & 187.8 & 81.4 & 205.8 & 152.7 \\
\hline Vitamin C & 149.1 & 112.8 & 112.5 & 144.8 \\
\hline Iron & 67.7 & 71.9 & 44.8 & 25.0 \\
\hline
\end{tabular}


Table 3 Intra-individual and inter-individual coefficients of variation for intakes of urban adult women $(n=50)$

\begin{tabular}{lcccccc}
\hline & \multicolumn{3}{c}{ Between-subject variation } & & \multicolumn{2}{c}{ Within-subject variation } \\
\cline { 2 - 3 } Nutrient & One 24-hour recall & Four 24-hour recalls & FFQ & & Four 24-hour recalls & FFQ \\
\hline Total energy & 38.1 & 30.8 & 34.8 & & 36.3 & 26.3 \\
Protein & 42.4 & 33.4 & 36.0 & & 40.1 & 22.9 \\
Carbohydrate & 43.4 & 32.2 & 30.8 & & 38.5 & 24.9 \\
Total fat & 48.3 & 37.5 & 45.2 & & 48.3 & 39.6 \\
Cholesterol & 87.7 & 63.3 & 70.2 & & 78.4 & 41.0 \\
Fibre & 58.4 & 42.9 & 19.8 & & 56.2 & 42.3 \\
Vitamin A & 205.8 & 143.8 & 77.0 & & 212.4 & 69.5 \\
Vitamin C & 112.5 & 69.1 & 46.9 & & 102.7 & 75.9 \\
Iron & 44.8 & 36.9 & 35.9 & & 49.6 & 37.5 \\
\hline
\end{tabular}

FFQ - food-frequency questionnaire.

recalls were used. Consumption of micronutrients, especially vitamins A and C, showed high relative variation in both cases.

Comparing the inter-individual CVs for some selected nutrients between adult women from the three studies (Table 2), similar values were observed for macronutrients in urban and rural women from the Sonora State Food Basket Study and in urban women from the dietary risk factors study (with the first recall). The inter-individual CVs of the Indian communities, however, were substantially lower, due to the simpler food pattern.

Between-person CVs for cholesterol and particularly vitamins $\mathrm{A}$ and $\mathrm{C}$ are the largest among nutrients of the three studies. Animal foods are consumed in these lowincome populations, although in small quantities and with low frequency. Fruit and vegetable intakes are low, and culturally and seasonally determined.

Analysing the inter-individual $\mathrm{CVs}$ of 50 randomly selected women from the total of 152 in the dietary risk factors study (Table 3), reduced CVs for selected nutrients were observed when comparing the estimation using a single 24-hour recall with the estimation by four 24-hour recalls, especially for vitamins. Using the estimates for the same nutrients by a semi-quantitative FFQ, the betweensubject CVs were not lower for macronutrients; however, they were lower for fibre and vitamins A and C.

Table 4 Ratio of intra-individual to inter-individual variance for some dietary components in the diets of urban women

\begin{tabular}{lcc}
\hline Nutrient & Urban women, Sonora, Mexico & NHS $^{*}$ \\
\hline Total energy & 1.4 & 1.9 \\
Protein & 1.5 & 3.9 \\
Carbohydrate & 1.5 & 1.2 \\
Total fat & 1.7 & 2.8 \\
Cholesterol & 1.6 & 6.8 \\
Fibre & 1.8 & - \\
Vitamin A & 2.1 & 11.7 \\
Vitamin C & 2.3 & 2.0 \\
Iron & 1.8 & 3.1 \\
\hline
\end{tabular}

${ }^{*}$ Nurses' Health Study, from Willett ${ }^{15}$.
In multiple 24-hour recalls, intra-individual CVs were higher than inter-individual CVs for all nutrients. But for dual administration of the semi-quantitative FFQ the effect was reversed for most nutrients; the exceptions were dietary fibre, vitamin $\mathrm{C}$ and iron.

Using the information on intra-individual and interindividual variations in selected nutrient intakes from the four 24-hour recalls, ratios of intra-individual $\mathrm{CV}$ to inter-individual $\mathrm{CV}$ were calculated. Table 4 shows a comparison of the ratios calculated for urban women from the dietary risk factors study with those reported for American women in the Nurses' Health Study ${ }^{15}$. Intraindividual to inter-individual $\mathrm{CV}$ ratios were lower for Mexican women than for US women. One can expect these results, because the diversity of Mexican diets is far lower than that for a developed country like the United States. The magnitude of the ratios, however, indicates that even in a less developed country there is intra-individual variability greater than the inter-individual variability that needs to be considered, especially for association analysis.

The data on intra-individual and inter-individual CV variations were used to deattenuate the correlation coefficients between the estimation of diet by four 24-hour recalls and the semi-quantitative FFQ in 50

Table 5 Correlation coefficients between intake estimates of selected food components by four 24-hour recalls and a semiquantitative food-frequency questionnaire (50 urban women from the dietary risk factors study)

\begin{tabular}{lcc}
\hline Food component & $\begin{array}{c}\text { Correlation } \\
\text { coefficient }\end{array}$ & $\begin{array}{c}\text { Corrected } \\
\text { by intra-/inter-subject } \\
\text { variation }\end{array}$ \\
\hline Energy & 0.63 & 0.73 \\
Protein & 0.52 & 0.61 \\
Carbohydrate & 0.46 & 0.54 \\
Total fat & 0.63 & 0.75 \\
Cholesterol & 0.53 & 0.63 \\
Fibre & 0.48 & 0.58 \\
Vitamin A & 0.08 & 0.10 \\
Vitamin C & 0.22 & 0.28 \\
Iron & 0.60 & 0.73 \\
\hline
\end{tabular}


Table 6 Urban women's intakes of nutrients, by season*. Values are given as mean \pm standard deviation

\begin{tabular}{lcccc}
\hline Nutrient & Spring & Summer & Autumn & Winter \\
\hline Energy & $1954 \pm 912^{\mathrm{a}}$ & $1564 \pm 784^{\mathrm{c}}$ & $1598 \pm 713^{\mathrm{d}}$ & $2160 \pm 1159^{\mathrm{a}}$ \\
Protein & $73 \pm 35^{\mathrm{a}}$ & $53 \pm 30^{\mathrm{c}}$ & $55 \pm 32^{\mathrm{d}}$ & $75 \pm 45^{\mathrm{a}}$ \\
Carbohydrate & $234 \pm 112^{\mathrm{a}}$ & $210 \pm 102^{\mathrm{c}}$ & $208 \pm 94^{\mathrm{d}}$ & $270 \pm 45^{\mathrm{b}}$ \\
Fat & $83 \pm 44^{\mathrm{a}}$ & $59 \pm 38^{\mathrm{c}}$ & $63 \pm 33^{\mathrm{d}}$ & $90 \pm 56^{\mathrm{a}}$ \\
Cholesterol & $384 \pm 343^{\mathrm{a}}$ & $247 \pm 246^{\mathrm{c}}$ & $211 \pm 201^{\mathrm{d}}$ & $410 \pm 416^{\mathrm{a}}$ \\
Vitamin A & $1759 \pm 3688^{\mathrm{a}}$ & $690 \pm 1014^{\mathrm{c}}$ & $707 \pm 1132^{\mathrm{d}}$ & $1370 \pm 3480^{\mathrm{b}}$ \\
Vitamin C & $93 \pm 79^{\mathrm{ab}}$ & $75 \pm 91 \mathrm{a}^{\mathrm{c}}$ & $77 \pm 98^{\mathrm{a}}$ & $86 \pm 88^{\mathrm{a}}$ \\
Iron & $17 \pm 10^{\mathrm{a}}$ & $12 \pm 7^{\mathrm{c}}$ & $12 \pm 8^{\mathrm{d}}$ & $17 \pm 10^{\mathrm{a}}$ \\
\hline
\end{tabular}

*Different superscripts by row indicate significantly different mean intakes.

women from the dietary risk factors study (Table 5). These results show how association analysis can be improved by correcting for the day-to-day intake variation among low-income women.

Finally, in the dietary risk factors study, the comparison of nutrient intakes between seasons (Table 6) shows that the differences in intake are mainly between winter and spring compared with summer and autumn $(P<0.05)$. Carbohydrate consumption, however, is higher during winter, and vitamins $\mathrm{A}$ and $\mathrm{C}$ show high variability as a consequence of different intakes by season. This last result is due to the greater availability of fruits and vegetables during spring and winter seasons. This availability coincides with the lower cost of these foods during the harvest seasons for fruit and vegetables in the region. This seasonality in consumption of fruit and vegetables should be taken into account in study design, especially if there is a focus on micronutrient consumption.

\section{Acknowledgements}

We thank Trinidad Quizán for helping with the data preparation and analysis.

\section{References}

1 Secretaría de Salud Pública (SSP). Encuesta Nacional de Enfermedades Crónicas. México: Dirección General de Epidemiología, SSP, 1993.

2 González Caamaño A, Pérez Balmes J, Nieto Sánchez CM, Vázquez Contreras A, Gaytán Flores E. Importancia de las enfermedades crónico-degenerativas dentro del panorama epidemiológico actual de México [Importance of chronic degenerative diseases in the current epidemiological panorama in Mexico]. Salud Pública Méx. 1986; 28(1): 3-13.

3 Hernández-Avila M, Romieu I, Parra S, Hernández-Avila J, Madrigal H, Willett W. Validity and reproducibility of a food frequency questionnaire to assess dietary intake of women living in Mexico City. Salud Pública Méx. 1998; 39: 133-40.

4 Quizan T, Ortega MI. Diseño y validación de una herramienta para identificar riesgo dietario en mujeres adultas de bajo ingreso [Design and validation of a food frequency questionnaire to evaluate the magnitude of noncommunicable chronic diseases in women from northwest Mexico]. Nutr. Clin. 2000; 2: 128-35.
5 Beaton GH, Milner J, Corey P, McGuire V, Cousins M, Stewart $\mathrm{E}$, et al. Sources of variance in 24-hour dietary recall data: implications for nutrition study design and interpretation. Am.J. Clin. Nutr. 1979; 32: 2546-9.

6 McPherson RS, Kohl HW III, García G, Nichaman MZ, Hanis CL. Food-frequency questionnaire validation among Mexican-Americans: Starr County, Texas. Ann. Epidemiol. 1995; 5: $378-85$.

7 Secretaría de Salud Pública, Dirección General de Estadística e Informática. Principales resultados de la estadística sobre mortalidad en México, 1997 [Results from health and mortality statistics in México, 1997]. Salud Pública Méx. 1998; 40(6): S17-23.

8 Chávez A, Chávez M, Roldán JA, Avila A. La transición epidemiológica nacional en alimentación y nutrición. In: Doode S, Pérez EP, eds. Sociedad, Economía y Cultura Alimentaria. México: Centro de Investigación en Alimentación y Desarrollo, A.C. y Centro de Investigaciones y Estudios Superiores en Antropología Social, 1994; 273-302.

9 Secretaría de Educación Pública (SEP) y Desarrollo Integral de la Familia (DIF). Segundo Censo Nacional de Talla; en niños de primer año de primaria [Second elementary school height census]. SEP-DIF Nacional, 1994.

10 Valencia ME, Hoyos LC, Ballesteros MN, Ortega MI, Palacios MR, Atondo JL. La dieta en Sonora: canasta de consumo de alimentos [Diet in Sonora: Food Basket Study]. Estud. Sociales. 1998; 8(15): 11-39.

11 Valencia ME, Esparza J, Montesinos H, Ravussin E, Bennet $\mathrm{PH}$, Schulz L. The diet of the Mexican Pima Indians: a potential environmental protective factor against type 2 diabetes and obesity. Br. J. Nutr. 2002 [submitted].

12 Ortega MI, Quizán T, Morales GG, Preciado M. Cálculo de la ingestión dietaria y coeficientes de adecuación a partir de: registro de 24 horas y frecuencia de consumo de alimentos [Food consumption and diet adequation analysis: 24 hourrecall and food frequency questionnaires]. Serie Evaluación del Consumo de Alimentos 1999; 1: 1-48.

13 Gebhardt SE, Matthews RH. Nutritive Value of Foods. US Department of Agriculture, Human Nutrition Information Service. Home and Garden Bulletin No. 72. Washington, DC: US Government Printing Office, 1988; 1-72.

14 Instituto Nacional de la Nutrición Salvador Zubirán (INN). Subdirección de Nutrición Experimental y Ciencia de los Alimentos. Tablas de Composición de Alimentos [Food Composition Tables], edición de aniversario. México: INN, 1980; $1-248$.

15 Willett W. Nutritional Epidemiology. Monographs in Epidemiology and Biostatistics. New York: Oxford University Press, 1990; 3-19, 69-91, 92-126, 245-71. 